Original Research

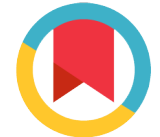

Check for updates

\title{
Psychosocial adjustment to cancer and its associated factors in patients undergoing chemotherapy: A cross-sectional study
}

\author{
Mohsen Taghadosi1 , Zeinab Tajamoli2, Mohammad Aghajani3,4,*
}

\begin{abstract}
1Trauma Nursing Research Center, Assistant Professor, Department of Internal Surgery, School of Nursing and Midwifery, Kashan University of Medical Sciences, Kashan, IR Iran

2MSC student of Intensive Care Nursing, Student Research Committee, Kashan University of Medical Sciences, Kashan, IR Iran

${ }^{3}$ Lecturer, Infectious Diseases Research Center, Kashan University of Medical Sciences, Kashan, IR Iran

4PhD Candidate, Student Research Committee, Kashan University of Medical Sciences, Kashan, IR Iran
\end{abstract}

\section{For correspondence:}

aghajani1362@yahoo.com aghajani_m@kaums.ac.ir

Competing interests: The authors declare that no competing interests exist.

Received: 16 October 2017 Accepted: 07 November 2017 Published: 21 December 2017

Copyright The Author(s) 2017. This article is published with open access by BioMedPress.

This article is distributed under the terms of the Creative Commons Attribution License (CC-BY 4.0) which permits any use, distribution, and reproduction in any medium, provided the original author(s) and the source are credited.

\section{Abstract}

Background: Adjustment to cancer refers to functions adopted by an individual for sustaining health and well-being, and leads to a better life and improved quality of life. Failure to adjust causes anxiety, depression, distress, and behavioral problems. The aim of study was to assess psychosocial adjustment to cancer and its associated factors in patients undergoing chemotherapy. Methods: This cross-sectional study recruited 260 cancer patients undergoing chemotherapy at a hospital center in Kashan, Iran in 2016. Data collection tools included demographic details, Psychological Adjustment to Illness Scale (PAIS), and adherence to religious beliefs (Temple). Samples were selected by convenience sampling method. Data were analyzed in SPSS-16 software using descriptive statistics, Chi-square test, and Pearson's correlation coefficient. Results: The mean age of participants was $54.76 \pm 13.82$ years, duration with cancer was $10.11 \pm 18.89$ months, duration of treatment with chemotherapy was

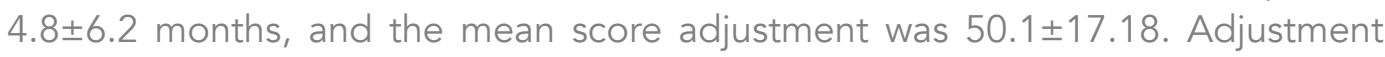
was found to be significantly related to education, marital status, financial status, employment, and adherence to religious beliefs, but not to age, duration with cancer, duration of chemotherapy, or place of residence. Patients with no metastasis were better adjusted compared to other groups, with a significant difference from the other groups. 
Conclusion: More than half of patients had moderate to high levels of adjustment. Patients with poor education, self-employment, no family support, low adherence to religious beliefs, and with metastasis displayed poorer adjustment levels; all of these negatively affected their adjustment to cancer. Thus, patients undergoing chemotherapy need greater family, social, and economic support for adjustment.

\section{Keywords}

Adjustment, Cancer, Chemotherapy

\section{Introduction}

The increasing incidence of cancer and its harmful effects in recent decades are among factors that have drawn the attention of specialists to cancer more than ever (Akbari, 2013). According to the World Health Organization (WHO) report, cancer is one of the most important diseases of the current century and the second leading cause of death next to cardiovascular diseases; more than 10 million people are diagnosed with a variety of cancers every year (Momeni et al., 2012). In Iran, cancer has been identified as the third leading cause of death after cardiovascular diseases and accidents (Rajabpour and Tavakolizadeh, 2012) . According to $\mathrm{WHO}$, by $2030,13.4 \%$ of deaths in Iran will be caused by cancer (Momeni et al., 2012).

Diagnosis of cancer causes psychological pressure in people more than any other diseases, and creates numerous problems in physical, psychological, social, economic, and family dimensions (Zemestani et al., 2013). Problems associated with this disease include pain, constant fatigue, nausea, vomiting, loss of appetite, diarrhea, anemia, shortness of breath, loss of libido, physical and structural changes, as well as alopecia, mastectomy, and amputation (arm and leg). Moreover, cancer can complicate various therapies and affect adjustment to the disease (e.g. patients may quit treatment instead of coping with the disease) (Zemestani et al., 2013). In cancer patients, adjustment refers to a series of attitudes and functions adopted by the individual for sustaining health, well-being, and overcoming cancer-induced stresses (Sadjadian et al., 2011).

Despite the problems associated with cancer, most patients are able to find effective ways of accepting and coping with their disease (Sadjadian et al., 2011). Adjustment is a continuous process and patients are faced with many challenges in solving cancer-related problems (Ahangar et al., 2013). Effective adjustment to the disease will lead to improved performance, better living, and improved quality of therapy (Samadzade et al., 2015). A good adjustment 
ensures the ability to affect positive health changes while poor adjustment leads to greater use of services, poor health outcomes, and reduced adherence to therapy. Ultimately, failure to adjust leads to the incidence of anxiety, depression, distress, and behavioral problems (Markani et al., 2016). Therefore, it is essential to examine adjustment of cancer patients and its related factors.

Only few studies have evaluated dimensions of adjustment in cancer patients. Sadjadian et al. reported moderate levels of adjustment in patients with breast cancer (Sadjadian et al., 2011). Yet, Zemestani et al. reported lower levels of social adjustment in cancer patients compared to healthy people (Zemestani et al., 2013). Previous studies have reported that there are many factors associated with adjustment in cancer patients (Trevino et al., 2014). Charmaine et al. (2016) found medication therapy, rest, relaxation, and distraction to be effective for adjustment to physical problems, while social support and religion were important for adjustment to psychological problems (D'Souza et al., 2016). Drageset et al. (2015) considered intimate family relationships, positive thinking, physical activity, self-care, nature, hobbies, and jobs (Drageset et al., 2016). Moreover, Jeremy et al. (2015) considered acceptance of the disease and humor (Shapiro et al., 2010) and Gonzales et al. (2015) considered emotional support, religious/spiritual strategies, benefit, belief in destiny, optimism, denial, distraction, and a fighting information-seeking spirit as factors affecting a patient's adjustment to cancer (Gonzales et al., 2015; Gonzalez et al., 2016). Hund et al. (2015) reported that most people with poorer education were females, and those with metastatic tumors have lower levels of adjustment (Hund et al., 2016). Brunault et al. investigated and confirmed the negative effects of major depression and young age on adjustment (Brunault et al., 2015), and Jeremy et al. also demonstrated the effect of reproach and surrender on poor adjustment (Shapiro et al., 2010).

One of the factors that can affect psychological health and create peace is faith in God and religious beliefs/rituals (Feghhi et al., 2014). Previous studies have shown that people with stronger religious beliefs are better adjusted to deal with difficult situations in life (Koenig, 2007). Hitter et al. reported that people with better religious/spiritual status have better physical health. Attention to a patient's religious/spiritual needs is, indeed, part of the holistic cancer therapeutic approach (Jim et al., 2015). In a study conducted by Andrews et al., a patient's trust in religious beliefs and prayers positively affect adjustment to cancer (Weaver and Flannelly, 2004). Meanwhile, Ahmadi et al. proposed that spiritual closeness to God or a superior power was the most important factor for adjustment to cancer (Ahmadi and Ahmadi, 2015). The results obtained by Trevino et al. show that people with negative or religious beliefs are more prone to psychological distress and risk of suicide (Trevino et al., 2014).

Yet, in some studies, no significant relationship was found between religious beliefs and patients' adjustment to cancer. Vellone et al. showed that religious practices have no effect on the treatment of cancer patients (Vellone et al., 2006). Paiva et al. reported a negative relationship between religious practice 
and quality of life prior to initiating chemotherapy in patients with breast cancer (Paiva et al., 2013). Moreover, in a study by Assimakopoulos et al., no significant relationship was observed between religion and adjustment to cancer (Assimakopoulos et al., 2009).

The capability to adjust to cancer is a challenging and threatening process, which is why it is important for healthcare personnel to deepen their understanding of the topic (Feghhi et al., 2014). Knowing how to support the patients and having the awareness of factors needed for adjustment can tremendously aid the patients (Momeni et al., 2012). Adjustment to diseases and religious beliefs are hugely affected by cultural and social conditions. Thus, investigating the factors associated with adjustment in different cultures helps to clarify this concept in patient care. Given the increasing incidence of cancer and its consequences, as well as its effects of adjustment to treatment and lifestyle changes of the patients, the present study aims to determine adjustment status and related factors in cancer patients undergoing chemotherapy.

\section{Materials-Methods}

This cross-sectional study was conducted on cancer patients attending the chemotherapy unit at a hospital center in Kashan, Iran from March 2015 to January 2016. This hospital is the only specialty and subspecialty center in the city of Kashan (near the capital of Iran), and is equipped with special injection units accessible by cancer patients referred for chemotherapy. The sample size of the study was 240 patients and was determined according to the study by Taghavi et al. (Taghavi et al., 2011), with 95\% confidence ( $d=9.064$, $s=48.32$ ). The sample size was increased to 265 patients to take into account possible withdrawal of $10 \%$.

The study inclusion criteria included definitive diagnosis of cancer, current treatment with chemotherapy, awareness of their disease, ability of verbal communication, normal hearing, no use of psychiatric medications, and willingness to participate in the study. Patients who were unwilling to cooperate or had critical conditions were excluded.

Convenience sampling method was used. The researcher/ investigator attended the bedside of eligible patients, and following introductions, explained the study objectives and gave assurances regarding data confidentiality and anonymity. The participants were assured that they were able to withdraw at any stage during the study. The participants were asked to carefully study the questionnaires and select the option that best described them. For patients unable to read and write, questions were read aloud and questionnaires were completed by the researcher based on the subjects' answers. Patients were interviewed in the ward or in a private room in the ward at their discretion. 
Data were collected using a three-part questionnaire consisting of demographic details (gender, age, marital status, education, economic status, duration of disease, employment, place of residence, and lifestyle), Psychological Adjustment to Illness Scale (PAIS), and adherence to religious beliefs questionnaire (Temple).

\section{Psychological Adjustment to Illness Scale (PAIS)}

The PAIS was developed in 1990 by Leonard and Derogates for evaluation of psychosocial adjustment to illness during the illness or its residual effects, and contains 46 items in a four-point scale (from 0 to 3 ) in seven dimensions. These dimensions include health care orientation, vocational environment, domestic environment, sexual relationships, extended family relations, social environment, and psychological distress. The mean total adjustment score was obtained by dividing total scores from each dimension by the number of items. Lower scores indicate more favorable adjustment and higher scores show unfavorable adjustment. In the present study, scores $<46$ showed high level of adjustment, 47-92 showed moderate adjustment, and $>93$ showed poor adjustment. Feghhi et al. (2014) reported the validity and reliability of the questionnaire with Cronbach's alpha of 0.94 (Feghhi et al., 2014).

\section{Adherence to religious beliefs questionnaire (Temple)}

This questionnaire was developed by Golzari (2000) to assess practicing religious beliefs, and has 25 items and four subscales, including individual religious behavior, collective religious behavior, practical behavior, and religious behavior. Each question has five options, with scores from 0 to 4 points. The total score for each question ranges from 0 (lowest) to 4 (highest); the total score for the entire test ranges from 0 (lowest) to 100 (highest) points. This test has a favorable content validity and reliability with Cronbach's alpha of 0.91 (Jafari et al., 2015).

\section{Ethical considerations}

The present research project was approved by the school's Research Council, and permission was obtained from the Ethics Committee of the Kashan University of Medical Science (Code: IR.KAUMS.REC.1395.11). After introducing themselves, the researcher explained the study objectives and obtained informed consents from the cancer patients undergoing chemotherapy. With the hope that the present study results could help alleviate patient condition, data was collected from all participants in order to complete the questionnaires. Given the sensitivity of the questions, the questionnaires were completed anonymously by the patients.

\section{Analysis of data}

Data were analyzed in SPSS-16 statistics program with descriptive central indices, and using Chi-square test for qualitative variables, T-test for quantitative 
variables, and Pearson correlation coefficient for the relationship between factors relating to adjustment.

\section{Results}

A total of 265 eligible patients completed the questionnaire. Of these, 5 questionnaires were not fully completed and were excluded from the study. Participants' mean age was 54 years, mean duration with cancer was 10 months, and mean duration of chemotherapy was 4 months. More than half of the patients (54.2\%) were female. The majority (83.5\%) were married, illiterate $(23.5 \%)$ or with primary school education (40\%). The results of the relationship between adjustment and underlying variables showed that patients' adjustment had no significant relationship with age, duration with cancer, duration of chemotherapy, or place of residence $(P>0.05)$. Mean adjustment score was higher in patients with higher levels of education (Bachelor's degree or higher) compared to other patients. Furthermore, adjustment score was higher in patients who lived with their parents or children, compared to other patients, but these differences were not statistically significant. Statistical tests showed significant relationships of psychosocial adjustment with marital status $(P=0.004)$, employment status $(P=0.004)$, and metastasis $(P=0.019)$, such that single and widowed patients, those with employment and moderate economic status, and those with no metastasis had better adjustment scores than other groups (Table 1).

Table 1. Relation between mean scores of psychosocial adjustment and demographic characteristics of patients undergoing chemotherapy in 2016

\begin{tabular}{|c|c|c|c|c|}
\hline \multicolumn{2}{|r|}{ Variables } & $\mathbf{N}$ & $\%$ & Test \\
\hline \multirow{2}{*}{ Gender } & Male & 119 & 45.8 & \multirow{2}{*}{$\begin{array}{l}t=1.06 \\
p=0.2\end{array}$} \\
\hline & Female & 141 & 54.2 & \\
\hline \multirow{5}{*}{ Education } & Illiterate & 61 & 23.5 & \multirow{5}{*}{$\begin{array}{l}F=2.11 \\
P=0.07\end{array}$} \\
\hline & Primary school & 104 & 40 & \\
\hline & Junior high & 24 & 9.2 & \\
\hline & Diploma & 41 & 15.8 & \\
\hline & $\begin{array}{c}\text { Bachelor's degree and } \\
\text { higher }\end{array}$ & 30 & 11.5 & \\
\hline \multirow{2}{*}{$\begin{array}{l}\text { Place of } \\
\text { residence }\end{array}$} & Private house & 126 & 48.5 & \multirow{2}{*}{$\begin{array}{l}t=0.03 \\
p=0.9\end{array}$} \\
\hline & Rented house & 25 & 9.6 & \\
\hline
\end{tabular}




\begin{tabular}{|c|c|c|c|c|}
\hline \multirow{2}{*}{ Metastasis } & With & 28 & 10.8 & \multirow{2}{*}{$\begin{array}{l}t=2.37 \\
p=0.019\end{array}$} \\
\hline & Without & 141 & 54.2 & \\
\hline \multirow{3}{*}{$\begin{array}{l}\text { Marital } \\
\text { status }\end{array}$} & Single (1) & 16 & 6.2 & \multirow{3}{*}{$\begin{array}{l}F=5.53 \\
P=0.004 \\
\text { (group } 2 \text { and 3) } \\
P=0.03 \\
\text { Tukey }\end{array}$} \\
\hline & Married (2) & 217 & 83.5 & \\
\hline & Widowed (3) & 27 & 10.4 & \\
\hline \multirow{6}{*}{$\begin{array}{c}\text { Employmen } \\
\text { t status }\end{array}$} & Employed (1) & 28 & 10.8 & \multirow{6}{*}{$\begin{array}{l}F=3.57 \\
P=0.004 \\
\text { (group } 1 \text { and 2) } \\
p=0.016 \\
\text { Tukey }\end{array}$} \\
\hline & Self-employed (2) & 48 & 18.5 & \\
\hline & Retired (3) & 38 & 14.6 & \\
\hline & Housewife (4) & 127 & 48.8 & \\
\hline & Worker (5) & 13 & 5 & \\
\hline & Student (6) & 6 & 2.3 & \\
\hline \multirow{3}{*}{$\begin{array}{c}\text { Economic } \\
\text { status }\end{array}$} & Low (1) & 123 & 47.3 & \multirow{3}{*}{$\begin{array}{l}F=4.57 \\
P=0.011 \\
\text { (group } 1 \text { and 2) } \\
P=0.014 \\
\text { Tukey }\end{array}$} \\
\hline & Moderate (2) & 117 & 45 & \\
\hline & High (3) & 20 & 7.7 & \\
\hline \multirow{4}{*}{$\begin{array}{l}\text { Living } \\
\text { conditions }\end{array}$} & Alone & 15 & 5.8 & \multirow{4}{*}{$\begin{array}{l}F=2.15 \\
P=0.09\end{array}$} \\
\hline & With parents & 12 & 4.6 & \\
\hline & With spouse & 119 & 45.8 & \\
\hline & With children & 8 & 3.1 & \\
\hline
\end{tabular}

According to the results obtained, psychosocial adjustment was moderate in more half of the patients $(56.9 \%$ ), high in $40.4 \%$, and low in $2.7 \%$. The mean adjustment score of participating patients was $50.10 \pm 17.18$, with the lowest score for the dimension of family relations (3.61 \pm 2.92$)$, indicating better adjustment. The highest score was for the dimension of vocational environment (7.58 4 4.67), indicating lower adjustment of patients in this dimension (Table 2).

Pearson's correlation coefficient showed an inverse and significant relationship between adjustment and adherence to religious beliefs and its dimensions $(P<0.05)$, such that higher adherence to religious beliefs led to higher adjustment to the disease. A correlation was also observed between dimensions of adjustment and adherence to religious beliefs, such that the dimension of health care orientation was found to have a significant and negative relationship with all dimensions of adherence to religious beliefs. Moreover, in the dimension of social environment, adjustment showed significant and negative relationships with collective religiosity and practical behavior dimensions, and adherence to religious beliefs in general. In the 
dimension of psychological disorders, significant and opposing relationships were observed with collective religiosity and practical behavior dimensions, and adherence to religious beliefs in general (Table 3). It is worth noting that lower adjustment scores are indicative of better adjustment status.

Table 2. Mean scores of various dimensions of adjustment in patients undergoing chemotherapy

\begin{tabular}{|c|c|c|c|}
\hline & Minimum & Maximum & Mean \pm SD \\
\hline Health care orientation & 0 & 16 & $5.97 \pm 3.94$ \\
\hline Vocational environment & 1 & 18 & $8.78 \pm 3.01$ \\
\hline Domestic environment & 0 & 20 & $8.62 \pm 4.1$ \\
\hline Sexual relations & 0 & 19 & $8.3 \pm 4.09$ \\
\hline Extended family relations & 0 & 11 & $3.61 \pm 2.92$ \\
\hline Social environment & 0 & 18 & $7.58 \pm 4.67$ \\
\hline Psychological distress & 0 & 21 & $7.14 \pm 4.59$ \\
\hline Total adjustment & 7 & 99 & $50.10 \pm 17.18$ \\
\hline
\end{tabular}

\section{Table 3. Correlation between various dimensions of adjustment and adherence to religious beliefs}

\begin{tabular}{|c|c|c|c|c|c|}
\hline $\begin{array}{l}\text { Religious beliefs/ } \\
\text { adjustment }\end{array}$ & $\begin{array}{c}\text { Individual religious } \\
\text { behavior }\end{array}$ & $\begin{array}{l}\text { Collective } \\
\text { religious behavior }\end{array}$ & $\begin{array}{l}\text { Practical } \\
\text { behavior }\end{array}$ & $\begin{array}{l}\text { Religious } \\
\text { behavior }\end{array}$ & Total \\
\hline $\begin{array}{l}\text { Health care } \\
\text { orientation }\end{array}$ & $\begin{array}{l}r=-0.18 \\
P=0.4\end{array}$ & $\begin{array}{l}r=-0.3 \\
P=0.001\end{array}$ & $\begin{array}{l}r=-0.26 \\
P=0.001\end{array}$ & $\begin{array}{l}r=-0.16 \\
P=0.009\end{array}$ & $\begin{array}{l}r=-0.26 \\
P=0.001\end{array}$ \\
\hline $\begin{array}{l}\text { Vocational } \\
\text { environment }\end{array}$ & $\begin{array}{l}r=0.03 \\
P=0.5\end{array}$ & $\begin{array}{l}r=-0.06 \\
P=0.3\end{array}$ & $\begin{array}{l}r=-0.004 \\
P=0.9\end{array}$ & $\begin{array}{l}r=0.06 \\
P=0.3\end{array}$ & $\begin{array}{l}r=0.004 \\
P=0.9\end{array}$ \\
\hline $\begin{array}{l}\text { Domestic } \\
\text { environment }\end{array}$ & $\begin{array}{l}r=-0.03 \\
P=0.5\end{array}$ & $\begin{array}{l}r=-0.08 \\
P=0.1\end{array}$ & $\begin{array}{l}r=-0.07 \\
P=0.2\end{array}$ & $\begin{array}{l}r=-0.01 \\
P=0.7\end{array}$ & $\begin{array}{l}r=-0.06 \\
P=0.2\end{array}$ \\
\hline Sexual relations & $\begin{array}{l}r=-0.1 \\
P=0.06\end{array}$ & $\begin{array}{l}r=-0.02 \\
P=0.6\end{array}$ & $\begin{array}{l}r=-0.01 \\
P=0.8\end{array}$ & $\begin{array}{l}r=0.001 \\
P=0.9\end{array}$ & $\begin{array}{l}r=-0.05 \\
P=0.4\end{array}$ \\
\hline $\begin{array}{l}\text { Extended family } \\
\text { relations }\end{array}$ & $\begin{array}{l}r=-0.007 \\
P=0.9\end{array}$ & $\begin{array}{l}r=-0.04 \\
P=0.4\end{array}$ & $\begin{array}{l}r=-0.006 \\
P=0.9\end{array}$ & $\begin{array}{l}r=-0.02 \\
P=0.7\end{array}$ & $\begin{array}{l}r=-0.02 \\
P=0.7\end{array}$ \\
\hline $\begin{array}{l}\text { Social } \\
\text { environment }\end{array}$ & $\begin{array}{l}r=-0.1 \\
P=0.06\end{array}$ & $\begin{array}{l}r=-0.2 \\
P=0.0001\end{array}$ & $\begin{array}{l}r=-0.1 \\
P=0.01\end{array}$ & $\begin{array}{l}r=-0.08 \\
P=0.1\end{array}$ & $\begin{array}{l}r=-0.1 \\
P=0.005\end{array}$ \\
\hline $\begin{array}{l}\text { Psychological } \\
\text { distress }\end{array}$ & $\begin{array}{l}r=-0.11 \\
P=0.06\end{array}$ & $\begin{array}{l}r=-0.23 \\
P=0.005\end{array}$ & $\begin{array}{l}r=-0.17 \\
P=0.005\end{array}$ & $\begin{array}{l}r=-0.11 \\
P=0.07\end{array}$ & $\begin{array}{l}r=-0.18 \\
P=0.003\end{array}$ \\
\hline Total adjustment & $\begin{array}{l}r=-0.9 \\
P=0.0001\end{array}$ & $\begin{array}{l}r=-0.9 \\
P=0.0001\end{array}$ & $\begin{array}{l}r=-0.9 \\
P=0.0001\end{array}$ & $\begin{array}{l}r=-0.7 \\
P=0.0001\end{array}$ & $\begin{array}{l}r=-0.18 \\
P=0.002\end{array}$ \\
\hline
\end{tabular}




\section{Discussion}

The present study results showed that more than half of patients undergoing chemotherapy had moderate levels of adjustment. Previous studies have reported different levels of adjustment. In agreement with the present study, a study conducted by Sadjadian et al. reported moderate adjustment scores in patients with breast cancer (Sadjadian et al., 2011). Yet, in the Zemestani study, compared to healthy people, cancer patients had lower levels of social adjustment (Zemestani et al., 2013). Previous studies of other chronic diseases also reported different results. Dempster et al. reported adjustment of diabetic patients as good, based on good and bad levels (Dempster et al., 2011). Feghhi et al. reported diabetic patients' adjustment as moderate (26), while Grinstein reported diabetic patients' adjustment over a five-year follow-up as poor (Grinstein et al., 2003). Khalili et al. reported poor adjustment levels in patients with heart failure, which was due to lack of knowledge about the nature of the disease and treatment regimens (Kalilzade et al., 2006). The differences in adjustment results can be attributed to differences in the type of disease, study populations, culture, and patients' coping strategies (Feghhi et al., 2014). Moreover, the use of different adjustment measuring scales can also lead to different results.

The results obtained showed no correlation between age and patients' adjustment. In agreement with our study, Sadjadian et al. did not observe significant differences between adjustment and age (Sadjadian et al., 2011). Moreover, in a study conducted by Brunault et al., younger patients with breast cancer used adjustment strategies less and had a poorer quality of life (Brunault et al., 2015). Tol et al. reported higher levels of adjustment with aging and attributed this to patients' sociability trend and improved experiences (Tol et al., 2012), which are different conclusions from our study. The difference in results can be attributed to the similarity of the participants' age.

Additionally, results from the present study show no gender-based difference in patients' psychosocial adjustment. In agreement with our study, Siston et al. also found no significant relationship between patients' psychosocial adjustment and gender (Siston et al., 2001), but in the Kaplan study psychosocial adjustment to disease was greater in men (De-Nour, 1982). In a study conducted by Hund et al., the number of men displaying signs of adjustment disorders was half that for women (Hund et al., 2016); this observation is not in accordance with our present study. Perhaps, use of other adjustment strategies by women can explain this difference.

In the present study, too, no correlation was observed between duration of cancer and patients' adjustment. Tol et al. showed that higher adjustment levels were associated with longer duration with diabetes (Tol et al., 2012). However, our present study did not show this; the difference could be attributed to the time of measuring adjustment in the study, which was during the acute phase of the disease (where chemotherapy was administered). 
According to our results, adjustment score was higher in patients with higher education compared to the rest, though not significantly. In agreement with our study, Hund et al. suggested that education was the most influential factor in patients' adjustment (Hund et al., 2016). Educated people often have greater social relations, are mostly employed and well-read, and consequently have greater adjustment with crises (Sodagar et al., 2013).

In the present study, patients that lived with their parents or children had better adjustment scores compared to the rest, but not significantly. In his study, Gonzales mentioned the positive effect of emotional support as an adjustment strategy for psychological and emotional health needed for acceptance of disease and well-being (Gonzalez et al., 2016). Gonzales' findings concur with those of the present study. This may be due to the role of family relations in the Iranian culture. At critical moments of therapy, family support can lead to heartening and encouragement of patients to accept therapy and the existing situation (Elahi et al., 2015).

In the present study, employed patients with moderate economic status had better adjustment level compared to other groups, which was significantly different. In agreement with the present study, Drageset's study showed that leisure and work were among factors affecting adjustment. Income and social support play a key role in adjustment of cancer patients (Drageset et al., 2016). In the present study, patients with no metastasis had better levels of adjustment compared to other groups, with a significant difference between them. Hund et al. also showed that the risk of adjustment disorders in patients with metastatic tumors was $80 \%$ higher than those with no metastasis (Gonzales et al., 2015), which also concurs with our study findings. The incidence of metastasis is a major stressor associated with anxiety and depression and among the negative factors in adjustment; this observation emphasizes the importance of greater support for patients in the metastatic phase of disease.

The present study results showed a significant and positive relationship between adjustment and adherence to religious beliefs and its dimensions, which concurs with results obtained by Andrews et al. According to their results, a positive relationship with God provides the individual with a sense of belonging and creates an emotional and peaceful source for facing lifethreatening diseases (Weaver and Flannelly, 2004). In a study conducted by Vallurupalli et al., the majority of patients (84\%) proposed reliance on religious beliefs as a way of coping with cancer (Vallurupalli et al., 2012). According to previous studies, in terms of culture, cancer patients in Iran are religious people who prefer to turn to religion for adjusting to critical situations in life, such as developing incurable diseases (Rezaei et al., 2008). Religious beliefs make psychological problems fade away and increase patient's adjustment with the disease, and help to maintain hope. Patients believe in God, the divine will, the reason behind events, God's power to help people, and gathering strength from a source of extraordinary power. Moreover, they have reliance on the power of God and the infallible Imams, and they display more adaptive 
responses through viewing death as rebirth (Zamanzadeh et al., 2014). Meaning, purpose, and hope in life are among components of consolidation of psychological health. Thus, in a meaningful and purposeful life, every arduous event, such as severe pressure and fatal disease, becomes meaningful (Jani and Molaee, 2014).

\section{Conclusion}

More than half of the patients had moderate and high levels of adjustment. Patients with poor education, self-employment, patients with no family support, and those with lower adherence to religious beliefs and with metastasis, displayed poorer adjustment levels. Indeed, all of these negatively affect adjustment to cancer. Thus, patients undergoing chemotherapy need greater family, social, religious, emotional, and economic support for adjustment. In the present study, adjustment had no significant relationship with age, duration with cancer, duration of chemotherapy, or place of residence. Study limitations included selection of samples from patients with special conditions undergoing chemotherapy, which could affect the homogeneity of the population. Thus, further analysis of groups of patients with specific cancers are recommended.

\section{Abbreviations}

PAIS: Psychological Adjustment to Illness Scale

WHO: World Health Organization

\section{Acknowledgements}

This article was due to the master science thesis that funded and supported by the Deputy of Research, Kashan University of Medical Sciences, Grant No: 95011. The researchers would like to express their gratitude to the personnel of the Beheshti hospital of Kashan, Iran. We appreciate all of the patients who cooperated and participated in this study. Also, the authors appreciate the research deputy of Kashan University of Medical Sciences for their support for the study.

\section{Author Contribution}

Mohsen Taghadosi and Mohammad Aghajani participated in the study conception as well as design, supervised the study, preformed the data analysis, and made critical 
revisions on the first draft of the manuscript; Zeinab Tajamoli participated in the study conception as well as design, preformed the data collection of the manuscript. All authors read and approve the final manuscript.

\section{References}

Akbari, M. (2013). Effectiveness of Mindfulness Training in Decreasing the Perceived Stress among the Patients Suffering from Breast Cancer. Journal of Thought \& Behavior in Clinical Psychology., 7(27), 7-16.

Momeni, T., Musarezaie, A., Karimian, J., Ebrahimi, A., . . .. (2012). The relationship between spiritual well-being and depression in Iranian breast cancer patients. Health Information Management, (0): 524.

Rajabpour, H., \& Tavakolizadeh, J. (2012). The relationship between emotional intelligence and adjusment in cancer patients in Mashhad. The Horizon of Medical Sciences., 18(1), 17-25.

Zemestani, M., Hasannejad, L., \& Nejadian, A. (2013). Comparison of quality of life, sleep quality and social adjustment of cancerous patients with intact individual in Ahvaz city. Majallah-i Pizishki-i Urumiyyah, 24(7), 471-482.

Sadjadian, A., Haghghat, S., Montazeri, A., Kazemnedjad, A., \& Alavinili, A. (2011). Post diagnosis coping strategies patients with breast cancer. Iranian Journal of Breast Disease., 4(3), 52-58.

Ahangar, R., Parvan, K., Hosseini, F. A., Abdollahzadeh, F., Seyedrasooli, E., \& Ghojazadeh, M. (2013). Stressors and coping methods of patients on hemodialysis in Tabriz Imam Reza teaching hospital in 2009. Razi Journal of Medical Sciences., 20(111), 1-11.

Samadzade, N., Poursharifi, H., and Babapour, J. (2015). The effectiveness of cognitivebehavioral therapy on the psycho-social adjustment to illness and symptoms of depression in individuals with type ii diabetes. Quarterly Clinical Psychology Studies 5, $77-96$.

Markani, A. K., Fard, M. K., Yaghmaei, F., Abbasi, M., \& Didarloo, A. (2016). Spirituality as Experienced by Iranian Muslim Oncology Nurses; A qualitative study. History of Medicine Journal (Quarterly), 6(21), 185-209.

Trevino, K. M., Balboni, M., Zollfrank, A., Balboni, T., \& Prigerson, H. G. (2014). Negative religious coping as a correlate of suicidal ideation in patients with advanced cancer. Psycho-Oncology, 23(8), 936-945. https://doi.org/10.1002/pon.3505

D'Souza, C.A., Antony, S., Thomas, B., and Murthy, S.G. (2016). Coping strategies used by cancer patients to deal with physical and psychological problems of chemotherapy. International Journal of Innovative Research and Development 5, 36-41.

Drageset, S., Lindstrøm, T. C., \& Underlid, K. (2016). "I just have to move on": Women's coping experiences and reflections following their first year after primary breast cancer surgery. European Journal of Oncology Nursing, 21, 205-211. https://doi.org/10.1016/ j.ejon.2015.10.005

Shapiro, J. P., McCue, K., Heyman, E. N., Dey, T., \& Haller, H. S. (2010). A naturalistic evaluation of psychosocial interventions for cancer patients in a community setting. 
Journal of Psychosocial Oncology, 28(1), 23-42. https://doi.org/ 10.1080/07347330903438891

Gonzalez, P., Nuñez, A., Wang-Letzkus, M., Lim, J.-W., Flores, K. F., \& Nápoles, A. M. (2016). Coping with breast cancer: Reflections from Chinese American, Korean American, and Mexican American women. Health Psychology, 35(1), 19-28. https:// doi.org/10.1037/hea0000263

Gonzales, F. A., Hurtado-de-Mendoza, A., Santoyo-Olsson, J., \& Nápoles, A. M. (2015). Do coping strategies mediate the effects of emotional support on emotional wellbeing among Spanish-speaking Latina breast cancer survivors? Psycho-Oncology.

Hund, B., Reuter, K., Härter, M., Brähler, E., Faller, H., Keller, M., . . Mehnert, A. (2016). stressors, symptom profile, and predictors of adjustment disorder in cancer patients. results from an epidemiological study with the composite international diagnostic interview, adaptation for oncology (cidi-o). Depression and Anxiety, 33(2), 153-161. https://doi.org/10.1002/da.22441

Brunault, P., Champagne, A. L., Huguet, G., Suzanne, I., Senon, J. L., Body, G., .... (2015). Major depressive disorder, personality disorders, and coping strategies are independent risk factors for lower quality of life in non-metastatic breast cancer patients. Psycho-Oncology.

Mehri Nejad, S.A., Ramezan Saatchi, L., and Paydar, S. (2017). Death Anxiety and Its Relationship with Social Support and Adherence to Religion in the Elderly. Iranian Journal of Ageing 11, 494-503.

Koenig, H. G. (2007). Spirituality and depression: A look at the evidence. Southern Medical Journal, 100(7), 737-740. https://doi.org/10.1097/SMJ.0b013e318073c68c

Jim, H. S., Pustejovsky, J. E., Park, C. L., Danhauer, S. C., Sherman, A. C., Fitchett, G., . . Salsman, J. M. (2015). Religion, spirituality, and physical health in cancer patients: A meta-analysis. Cancer, 121(21), 3760-3768. https://doi.org/10.1002/cncr.29353

Weaver, A. J., \& Flannelly, K. J. (2004). The role of religion/spirituality for cancer patients and their caregivers. Southern Medical Journal, 97(12), 1210-1214. https://doi.org/ 10.1097/01.SMJ.0000146492.27650.1C

Ahmadi, F., \& Ahmadi, N. (2015). Nature as the most important coping strategy among cancer patients: A Swedish survey. Journal of Religion and Health, 54(4), 1177-1190. https://doi.org/10.1007/s10943-013-9810-2

Vellone, E., Rega, M. L., Galletti, C., \& Cohen, M. Z. (2006). Hope and related variables in Italian cancer patients. Cancer Nursing, 29(5), 356-366. https://doi.org/ 10.1097/00002820-200609000-00002

Paiva, C. E., Paiva, B. S. R., de Castro, R. A., de Pádua Souza, C., de Paiva Maia, Y. C., Ayres, J. A., . . . (2013). A pilot study addressing the impact of religious practice on quality of life of breast cancer patients during chemotherapy. Journal of Religion and Health, 52(1), 184-193. https://doi.org/10.1007/s10943-011-9468-6

Assimakopoulos, K., Karaivazoglou, K., Ifanti, A. A., Gerolymos, M. K., Kalofonos, H. P., \& Iconomou, G. (2009). Religiosity and its relation to quality of life in Christian Orthodox cancer patients undergoing chemotherapy. Psycho-Oncology, 18(3), 284-289. https:// doi.org/10.1002/pon.1402

Taghavi, M., Kalafi, E., Talei, A., Dehbozorgi, G., \& Taghavi, S. M. A. (2011). Investigating the Relation of Depression and Religious Coping and Social Support in Women with Breast Cancer. Majallah-i Danishkadah-i Pizishki-i Isfahan, 28(115). 
Feghhi, H., Saadatjoo, A., \& Dastjerdi, R. (2014). Psychosocial adaptation in patients with type 2 diabetes referring to Diabetes Research Center of Birjand in 2013. Modern Care Journal., 10(4), 249-256.

Jafari, E., Hajloo, N., \& Mohammadzadeh, A. (2015). The Relationship between the Practice of Religious Beliefs, Spiritual Well Being, General Health and Coping Styles in Soldiers. Journal of Military Medicine., 16(4), 191-196.

Dempster, M., McCarthy, T., \& Davies, M. (2011). Psychological adjustment to Type 2 diabetes and relationship quality. Diabetic Medicine, 28(4), 487-492. https://doi.org/ 10.1111/j.1464-5491.2010.03214.x

Grinstein, G., Muzumdar, R., Aponte, L., Vuguin, P., Saenger, P., \& DiMartino-Nardi, J. (2003). Presentation and 5-year follow-up of type 2 diabetes mellitus in AfricanAmerican and Caribbean-Hispanic adolescents. Hormone Research in Paediatrics, 60(3), 121-126. https://doi.org/10.1159/000072523

Kalilzade, H., Nanbakhsh, J., \& Yaghobi, M. (2006). Check the compatibility of heart failure patients with complications of the disease in the Training Center - Taleghani Hospital in Urmia. Journal of Nursing and Midwifery Urmia University of Medical Sciences., 4(4), 154-160.

Tol, A., Majlessi, F., Rahimi, F.A., Shojaeezadeh, D., and Mohebbi, B. (2012). Factors associated with supportive and coping obstacles of adjustment with type II diabetes. Health System Research 8, 1088-1097.

Siston, A. K., List, M. A., Daugherty, C. K., Banik, D. M., Menke, C., Cornetta, K., \& Larson, R. A., \& the Siston a. (2001). Psychosocial adjustment of patients and caregivers prior to allogeneic bone marrow transplantation. Bone Marrow Transplantation, 27(11), 1181 1188. https://doi.org/10.1038/sj.bmt.1703059

De-Nour, A. K. (1982). Psychological adjustment to illness scale (PAIS): A study of chronic hemodialysis patients. Journal of Psychosomatic Research, 26(1), 11-22. https:// doi.org/10.1016/0022-3999(82)90058-7

Sodagar, S., Ahadi, H., Jomehri, F., Rahgozar, M., \& Jahani, M. (2013). Quality of Life and Physical well-being after bone marrow transplantation in patients with acute leukaemia. [J Kermanshah Univ Med Sci]. Majallah-i Danishgah-i Ulum-i Pizishki-i Kirmanshah, 16(8), 610-616.

Elahi, N., Kaardani, M., Alhani, F., \& Tali, S. (2015). Transplantation living with mastectomy: Explaining the experiences adaptation with mastectomy of young women undergoing chemotherapy. Journal of Urmia Nursing And Midwifery Faculty., 12(10), 908-918.

Vallurupalli, M. M., Lauderdale, M. K., Balboni, M. J., Phelps, A. C., Block, S. D., Ng, A. K., ... Balboni, T. A. (2012). The role of spirituality and religious coping in the quality of life of patients with advanced cancer receiving palliative radiation therapy. The Journal of Supportive Oncology, 10(2), 81-87. https://doi.org/10.1016/j.suponc.2011.09.003

Rezaei, M., Seyedfatemi, N., and Hosseini, F. (2008). Spiritual Well-being in Cancer Patients who Undergo Chemotherapy. Hayat 14, 104-104.

Zamanzadeh, V., Rassouli, M., Abbaszadeh, A., Nikanfar, A.-R., Alavi-Majd, H., MirzaAhmadi, F., . . .. (2014). Spirituality in cancer care: A qualitative study. Journal of Qualitative Research in Health Sciences., 2(4), 366-378.

Jani, S., \& Molaee, M. (2014). JANGI GS, Pouresmali A. Effectiveness of Cognitive Therapy Based on Religious Believes on Death Anxiety. Social Adjustment and Subjective Well-being in the Cancer Patients. 